ORIGINAL ARTICLE

\title{
The Prevalence and Risk Factors Associated with Nasal Methicillin- Resistant Staphylococcus Aureus Colonization among Children in a Tertiary Hospital in Nigeria
}

\author{
Kemi Elizabeth Tuta ${ }^{1,2^{*}}$, Abiola Olukemi Okesola ${ }^{1}$, Chukwuma David \\ Umeokonkwo ${ }^{2,3}$
}

\footnotetext{
OPEN ACCESS

Citation: Kemi Elizabeth Tuta, Abiola Olukemi Okesola, Chukwuma David Umeokonkwo. The Prevalence and Risk Factors Associated with Nasal Methicillin-Resistant Staphylococcus Aureus Colonization among Children in a Tertiary Hospital in Nigeria. Ethiop $\mathrm{J}$ Health

Sci.2017;29(4):487.doi:http://dx.doi.org/ 10.4314/ejhs.v29i4.10

Received: May 19, 2019

Accepted: May 28, 2019

Published: July 1, 2019

Copyright: (C) 2019 Kemi E.T., et al.

This is an open access article distributed under the terms of the Creative Commons Attribution License, which permits unrestricted use, distribution, and reproduction in any medium, provided the original author and source are credited. Funding: Nil

Competing Interests: The authors declare that this manuscript was approved by all authors in its form and that no competing interest exists.

Affiliation and Correspondence:

${ }^{1}$ University College Hospital,

Ibadan, Oyo State, Nigeria

${ }^{2}$ Nigeria field Epidemiology

laboratory Training Programme, Abuja, Nigeria

${ }^{3}$ Department of Community

Medicine, Federal Teaching

Hospital Abakaliki, Ebonyi State,

Nigeria

*Email: kempathology@gmail.com
}

\section{ABSTRACT}

BACKGROUND: Nasal methicillin-resistant Staphylococcus aureus (MRSA) colonization is of public health concern due to increased risk of developing invasive infections and the therapeutic challenges. This concern is more among the vulnerable group. We determined the prevalence and associated risk factors of MRSA nasal carriage among children in a tertiary hospital in Nigeria.

METHOD: We conducted a hospital-based, cross-sectional study among 300 children attending the outpatient clinic of a tertiary hospital recruited through systematic sampling technique. An interviewer-administered, structured questionnaire was used to obtain sociodemographic characteristics and exposure factors. Nasal swabs samples were collected and inoculated on mannitol salt agar and subcultured on nutrient agar to isolate Staphylococcus aureus. We used the conventional Polymerase Chain Reaction (PCR) technique to detect the presence of mecA gene for MRSA. We calculated the prevalence, prevalence odds ratio to determine risk factors for MRSA acquisition at 5\% level of significance.

RESULTS: The median age was 1.7 years (6 months-16 years). Males accounted for $60.7 \%$, and $75 \%$ of the participants were under 5 years. Staphylococcus aureus colonization was found in $36.3 \%$ of the participants while $5.3 \%$ of the participants had MRSA identified by detecting the mec $A$ gene. History of recent surgery in the last six months was the only independent predictor of nasal MRSA colonization among the participants (aOR=12.5; 95\%CI: 2.7-50.0.)

CONCLUSION: The high prevalence of MRSA colonization observed among the children in this study suggests the need to consider screening children with history of previous surgery as infection control and prevention intervention for MRSA.

KEYWORD: MRSA, Children, Staphylococcus aureus 


\section{INTRODUCTION}

Methicillin-resistant Staphylococcus aureus (MRSA) is a Gram-positive bacterium that is resistant tomethicillin (a member of the penicillin family), andmany other $\beta$-lactam antimicrobials such as penicillin, cephalosporins, and macrolides. Methicillin-resistant Staphylococcus aureus strains are usually resistant to several groups of broad-spectrum antibiotics that are used on a large scale in the hospital (1). It is a significant cause of both healthcare and community associated infections globally with great economic and clinical impacts (2-4).

Methicillin-resistant Staphylococcus aureus infection and colonization have been reported in humans both inside and outside hospital environments in Nigeria. Several reports of human MRSA infections have been documented with prevalence ranging from $34.7 \%$ to $76.7 \%$ (5-9). A lower MRSA prevalence rate of $20 \%$ has also been reported in Zaria, Nigeria, among nonhospital sources (10). Isolating MRSA among patients has a serious implication because they pose high risk of systemic infection, wound infection with resistant antibiotics, etc. A study has, however, posited that patients going for clean elective surgeries need not be screened for MRSA (11).

The mechanism of increased spreading under antibiotic pressure may have contributed to the worldwide increase in the prevalence of MRSA in hospitals (1). Resistance in MRSA is mediated by a gene (mec A) that encodes the production of an altered penicillin-binding protein (PBP2a), which does not allow for the binding of $\beta$-lactams to the bacterial cell wall (12). Since $\beta$-lactams exert antibacterial activity by binding and inhibiting enzymes necessary for bacterial cell wall synthesis, these antimicrobials are not therefore effective against MRSA.

The isolation of MRSA nasal colonization were initially among hospitalized patients. This has rapidly spread to include healthy individuals in the communities. The worrisome dismenssion is isolation in vulnerable groups like children, with potential risk of systemic infections (13). This necessitated the need to examine children in our environment and identify any associated risk factors to MRSA colonization. We conducted this study to assess the prevalence and risk factors of nasal MRSA colonization among children attending the outpatient clinic of a tertiary hospital in Southwest Nigeria and enable health policy makers to develop and implement an effective MRSA control policy in the hospital.

\section{METHODS}

Study setting and design: The study was conducted at the University College Hospital Ibadan, an 820 bedded tertiary hospital located in Oyo State, Southwest Nigeria. It runs Paediatric Outpatient Clinics daily. The clinic sees about 2030 patients daily.

The study was a hospital-based, crosssectional one among children of less than 16 years of age attending the Children Outpatient Clinic in University College Hospital. We included the eligible children whose mothers or guardians gave consent whereas children whose mothers or guardians did not give consent were excluded.

Sample size and sampling technique: We estimated the sample size using the formula for single proportion using the following parameters: precision of $5 \%$, prevalence of MRSA among children in previous study of $22.1 \%$ and level of significance of $5 \%$. We adjusted for non-response using $10 \%$ and conducted continuity correction. The estimated sample size was 300 children. We used systematic sampling technique to recruit the eligible children from the clinics. Intervieweradministeredstructured questionnaire was used to obtain sociodemographic characteristics and exposure factors of nasal MRSA colonization.

Specimen collection and handling: We collected nasal swab samples from each participant. The two anterior nares of each enrolled patient were swabbed with sterile cotton wool swabs moistened with normal saline. The nasal swabs were transported immediately to the laboratory and inoculated within 2 hours. The swabs were plated on mannitol salt agar (MSA) and nutrient agar and then incubated at 35-37degree Celsius within 1824 hours. The Staph aureus isolated was identified by colonial morphology, Gram stain, slide

DOI: http://dx.doi.org/10.4314/ejhs.v29i4.10 
coagulase test and confirmed by tube coagulase test. Pure colonies of Staphylococcus aureus isolated were sub-cultured in a $20 \%$ glycerol with tryptic soy broth at -20 degrees Celsius, for further processing. Methicillin-resistant Staphylococcus aureus gene (Mec A) primer, conventional PCR instrument, DNA extraction kit, Master Mix containing each DNA taq polymerase $1.25 \mu 1$ per reaction, buffer $\mathrm{B}$ of $50 \mathrm{mM} \mathrm{KCl}$, TRIS $10 \mathrm{mM}$, $1.5 \mathrm{mM}, \mathrm{MgCl}_{2}, 200 \mu \mathrm{m}$ dNTP, blue dye, yellow dye, Eppendorf tubes, Universal containers, Micropipette, Micropipette tips, Micro centrifuge machine, Vortex machine, Electrophoresis tank, Ultra violet box, Ethidium bromide (EtBr), DNA ladder and Jena Bioscience Bacteria DNA preparation kit were used according to the manufacturer's instruction.

About 2 distinct colonies of sub cultured Staphylococcus aureus suspension was harvested by centrifugation at $10000 \mathrm{rpm}$ for one minute, and the supernatant was discarded; then $300 \mu$ of lysis buffer and $2 \mu 1$ of RNase A were added to the pellet. The mixture was vortexed vigorously for 30 to 60 seconds and $8 \mu 1$ of proteinase $\mathrm{K}$ was added to it and then incubated at 60 degree Celsius for 10 min. The mixture was cooled down for 5 minutes, $300 \mu 1$ of binding buffer was added to it and was vortexed briefly. The solution was placed on ice for 5 minutes and centrifuged for 5 minutes at $10000 \mathrm{rpm}$. A spin column was placed into a $2 \mathrm{ml}$ collection tube, and the mixture was discarded into it. Lysate was pipetted directly into the spin column, centrifuged for one minute at 10000rpm and the flow-through was discarded. About $500 \mu 1$ of washing buffer was added into the spin column, centrifuged for 30 seconds at 10000rpm and the flow-through was discarded. Another $500 \mu 1$ of washing buffer was added into the spin column, centrifuged for another 30 seconds at 10000rpm and the flow-through was discarded. The spin column was centrifuged again at $10000 \mathrm{rpm}$ for one minute to remove the residual washing buffer. The $2 \mathrm{ml}$ tube was discarded; the spin column was placed in the elution tube and 40 to $50 \mu 1$ of elution buffer was added into the center of the spin column. It was incubated at room temperature for one minute and centrifuged at 10000rpm for 2 minutes. The extracted DNA was stored at -20 degrees Celsius.

Protocol For PCR: Primer sequences used for methicillin resistance Staphylococcus aureus (MecA) gene primer were MecAF5'GTGGAATTGGGCAATACACC-3' and MecA-R 5'AGTTCTGCAGTACCGGAT-3' (Biomers.net,Germany). Then, $20 \mu 1$ was prepared for each of the samples. The PCR set up consisted of $5 \mu 1$ of DNA extract, $0.40 \mu 1$ of primers (forward and reverse), $10.60 \mu 1$ of PCR water, $4 \mu 1$ of Master mix (reaction buffer $\mathrm{B}, \mathrm{MgCl}_{2}, \mathrm{DNTP}$ ), all in a tube. All tubes were sealed and briefly centrifuged then transferred into the PCR machine. Amplification was done with the following protocol: initial denaturation at 95 degree Celsius for 5 minutes, then 30 cycles of denaturation at 95 degrees Celsius for 40 seconds, annealing at 57 degree Celsius for 30 seconds, extension at 72 degree Celsius for 60 seconds and final extension at 72 degree Celsius for 7 minutes. Each amplification run contained one negative control. After amplification, electrophoretic separation of PCR products was performed on $1.5 \%$ agarose gel stained with ethidium bromide, and visualized by UV illumination.

Electrophoresis: Twenty microliter $(20 \mu \mathrm{l})$ of each of the PCR product was loaded into separate wells of $1.5 \%$ agarose gel stained with $0.5 \mu \mathrm{g} / \mathrm{ml}$ ethidium bromide and assembled in a gel electrophoretic tank containing $1 \mathrm{x}$ Tris-borateEDTA buffer. Then, $10 \mu 1$ of $100 \mathrm{bp}$ DNA ladder was loaded into the first well followed by the positive and negative controls in the next 2 wells; the amplicon was then serially loaded into the other wells. After loading, the electrophoretic tank was switched on and programmed to transmit 45 volts electric current across the gel for about 45 minutes. After electrophoresis, the agarose gel was transferred to a gel photo documentation system, UV-trans illuminator (byClinix Science Instruments Co Ltd model number 800 serial number76526), and the result was read on a connected computer.

Interpretation of laboratory result: Samples corresponding to electrophoretic lanes with band at a level equivalent to $536 \mathrm{bp}$ on the DNA molecular weight marker were documented as positive for mecA DNA. The samples that did not 
meet this criterion were considered as negative. Quality control: To confirm proper performance of the amplification process, a known MRSA DNA-positive control was run along with the samples during every PCR run and always gave a positive band at $536 \mathrm{bp}$ mark. To confirm absence of contamination, a negative control using RNA/DNA free water was included in every PCR run and always showed no band.

Ethical approval: The study protocol was approved by the Institutional Review Board of the University of Ibadan and the University College Hospital both in Southwest Nigeria with approval number UI/EC/15/0156. Written informed consent was obtained from the parents or guardians of the participants and ascent obtained from the older participants.

\section{RESULTS}

The median age of the sample population was 1.7 years (6 months - 16 years). Males constituted $60.7 \%(182 / 300)$. Under 5 years were the majority constituting $75 \%(219 / 300)$ of the study population. The majority of the fathers $(63.4 \%)$ and mothers $(60.0 \%)$ had attained tertiary level of education (Table 1).

The majority $(78.6 \%)$ of the participants were Yorubas by ethnicity, and others (21.4\%) were composed of other tribes. Most of the study participants $(91.7 \%)$ had no surgery in the last six months, (63.7\%) were not recently hospitalized, the majority of the respondents were not residents in a long-term care facility and (77.3\%) had no history of previous usage of antibiotics in the last six months (Table 2).

Staphylococcus aureus colonization was detected in $36.7 \%(110 / 300)$ of the participants whereas MRSA colonization was found in 5.3\% $(16 / 300)$ of the participants. We conducted bivariate analysis of the factors associated with nasal MRSA colonization. Age of children and history of recent surgery was found to be associated (Table 3). When these variables were modelled in logistic regression, history of recent surgery remained a significant predictor of nasal MRSA colonization (aOR 5.2; 95\% CI: 1.6016.93, Table 4).
Table 1: Socio-demographic characteristics of participants

\begin{tabular}{|c|c|c|}
\hline Variable & $\begin{array}{l}\text { Frequency } \\
(\mathrm{N}=300)\end{array}$ & y \\
\hline \multicolumn{3}{|l|}{ Sex } \\
\hline Male & 182 & 60.7 \\
\hline Female & 118 & 39.3 \\
\hline \multicolumn{3}{|l|}{ Age(years) } \\
\hline $0-4$ & 225 & 75.0 \\
\hline $5-9$ & 45 & 15.0 \\
\hline$\geq 10$ & 30 & 10.0 \\
\hline \multicolumn{3}{|l|}{ Religion } \\
\hline Christianity & 182 & 60.7 \\
\hline Islam & 118 & 39.3 \\
\hline \multicolumn{3}{|c|}{ Father's Occupation } \\
\hline Self Employed & 144 & 48.0 \\
\hline Civil Servant & 88 & 29.3 \\
\hline Trading & 37 & 12.3 \\
\hline Farming & 9 & 3.0 \\
\hline Others & 22 & 7.4 \\
\hline \multicolumn{3}{|c|}{ Mother's Occupation } \\
\hline Self Employed & 137 & 45.7 \\
\hline Civil Servant & 62 & 20.7 \\
\hline Trading & 62 & 20.7 \\
\hline Farming & 5 & 1.6 \\
\hline Others & 34 & 11.3 \\
\hline \multicolumn{3}{|l|}{ Father's Education } \\
\hline No formal & 10 & 3.3 \\
\hline Primary & 26 & 8.7 \\
\hline Secondary & 75 & 25.0 \\
\hline Tertiary & 189 & 63.0 \\
\hline \multicolumn{3}{|c|}{ Mother's Education } \\
\hline No Formal & 10 & 3.3 \\
\hline Primary & 25 & 8.3 \\
\hline Secondary & 85 & 28.4 \\
\hline Tertiary & 180 & 60.0 \\
\hline \multicolumn{3}{|l|}{ Family Size } \\
\hline$<6$ & 235 & 78.3 \\
\hline$\geq 6$ & 65 & 21.7 \\
\hline \multicolumn{3}{|c|}{$\begin{array}{l}\text { Number of people } \\
\text { sleeping in a room }\end{array}$} \\
\hline$<5$ & 275 & 91.7 \\
\hline$\geq 5$ & 25 & 8.3 \\
\hline
\end{tabular}


Table 2: Clinical characteristics of the participants

\begin{tabular}{lll}
\hline Variable & Frequency & Percentage \\
\hline Recent surgery & 25 & \\
$\quad$ Yes & 275 & 8.3 \\
$\quad$ No & & 91.7 \\
Recent hospitalization & 123 & 41.0 \\
$\quad$ Yes & 177 & 59.0 \\
$\quad$ No & 22 & \\
Residence in long term care facility & 7.3 \\
$\quad$ Yes & 278 & 92.7 \\
$\quad$ No & & \\
Use of antimicrobial last one year & 68 & 22.7 \\
$\quad$ Yes & 232 & 77.3 \\
$\quad$ No & & \\
Contact with frequently hospitalized person & 15 & 5.0 \\
$\quad$ Yes & 285 & 95.0 \\
$\quad$ No & & \\
History of chronic illness & 34 & 11.3 \\
$\quad$ Yes & 266 & 88.7 \\
$\quad$ No & & \\
History of household contact with bedridden & 13 & 4.3 \\
$\quad$ Yes & 287 & 95.7 \\
$\quad$ No & & \\
Current episode of URTI & 35 & 11.7 \\
$\quad$ Yes & 265 & 88.3 \\
$\quad$ No & & \\
History of living in a hostel & 10 & 3.3 \\
$\quad$ Nes & 290 & 96.7 \\
\hline No & & \\
\hline
\end{tabular}

Table 3: Relationship between MRSA colonization and socio-demographic and clinical characteristics of the participants

\begin{tabular}{|c|c|c|c|c|}
\hline Variable & MRSA & No MRSA & Chi square & p value \\
\hline \multicolumn{5}{|c|}{ Age group (years) } \\
\hline $0-4$ & $9(4.0)$ & $216(96.0)$ & 3.17 & 0.075 \\
\hline Others & $7(8.3)$ & $68(90.7)$ & & \\
\hline \multicolumn{5}{|c|}{ History of recent surgery } \\
\hline Yes & $5(20.0)$ & $20(80.0)$ & 11.62 & $<0.001$ \\
\hline No & $11(4.0)$ & $264(96.0)$ & & \\
\hline \multicolumn{5}{|c|}{ History of hospitalization } \\
\hline Yes & $5(4.1)$ & $118(95.9)$ & 0.66 & 0.415 \\
\hline No & $11(6.2)$ & $166(93.8)$ & & \\
\hline \multicolumn{5}{|c|}{ History of antimicrobial use } \\
\hline Yes & $4(5.9)$ & $64(94.1)$ & 0.53 & 0.819 \\
\hline No & $12(5.2)$ & $220(94.8)$ & & \\
\hline \multicolumn{5}{|c|}{ History of stay in a long-term health facility } \\
\hline Yes & $1(4.6)$ & $21(95.4)$ & 0.03 & 0.864 \\
\hline No & $15(5.4)$ & $263(94.6)$ & & \\
\hline \multicolumn{5}{|c|}{ History of bedridden household member } \\
\hline Yes & $1(7.7)$ & $12(92.3)$ & 0.15 & 0.699 \\
\hline No & $15(5.2)$ & $272(94.8)$ & & \\
\hline
\end{tabular}

DOI: http://dx.doi.org/10.4314/ejhs.v29i4.10 
Table 4: Logistic regression of the factors associated with MRSA colonization

\begin{tabular}{lll}
\hline Risk factors & Adjusted OR & $95 \% \mathrm{CI}$ \\
\hline Age group (years) & & \\
$\quad 0-4$ & 1 & $0.70-5.86$ \\
$\quad$ Others & 2.0 & \\
Recent surgery & & $1.60-16.93$ \\
$\quad$ Yes & 5.2 & \\
No & 1 & \\
\hline
\end{tabular}

\section{DISCUSSION}

The prevalence of nasal carriage of Staphylococcus aureus varies among geographical regions, hospital settings, populations and people with different conditions. This study has shown the overall anterior nares prevalence rate of Staphylococcus aureus among children attending outpatient clinic. The prevalence of Staphylococcus aureus colonization observed was similar to previous findings in Niger Delta, Nigeria, USA and Japan among healthy adults $(14,15)$. Our finding is also in keeping with that obtained in Iran where the prevalence of $26.6-52.3 \%$ has been reported (13). Anterior nares are the main reservoirs of $S$. aureus in children and adults. Nasal cavity colonization with $S$. aureus that is a major risk factor for different infections (16-18).

Hence, this is a worrisome situation given that these children still have poorly developed immune system and are not able to mount resistance as observed in adults. They thus need to be protected from the risks posed by these invasive organisms $(19,20)$. In Abia State, Isoutheast Nigeria, higher prevalence of $50 \%$ nasal colonization in hospital and non-hospital subjects has been reported (21). However, a lower prevalence of $14 \%$ has been reported among medical students in Lagos, Southwest Nigeria (22).

There is a need to eliminate its virulent strains because of their ability to cause infections in colonized individuals both in the hospital and community settings $(19 ; 20)$. Our study provided information on the level of nasal MRSA colonization among children in the hospital. The prevalence of asymptomatic nasal MRSA colonization among the study population in our study with the use of molecular technique (PCR) was 5.3\%. The prevalence rate in this study may be considered low for a hospital. However, the prevalence of nasal MRSA colonization in this study was higher than those reported in Maiduguri, Nigeria of $0.01 \%(23)$, and $1.5 \%$ in USA (24), Ireland (5\%) and UK (2\%) (25) but lower than the $15 \%$ reported in another study in Abakaliki, Ebonyi State, Nigeria (26), the $13.6 \%$ in Taiwan (27) and the $14.85 \%$ in Zaria, Nigeria (28). These variations may be attributed to the varying populations under study.

The highest yield of nasal MRSA colonization in this study was from the age group of 5-10 years compared to a previous study that reported the highest nasal colonization among children aged 1-6 years (29). This is believed to be due to poorly developed immune system which makes them vulnerable to bacterial invasion especially when hospitalized. It could also be due to period of peak colonization with respiratory organisms. This is a phenomenon known as bacterial interference in which one bacterial strain prevents colonization by another strain which plays an important role in establishing the pathogen (1). The risk factor for MRSA nasal colonization in our study was the history of previous surgery in the last six months. Similar observations were made in previous studies $(30,31)$. We observed that the nasal MRSA carriage in our study is independent of previous hospitalization, antibiotic use, number of persons living in the room, household contact bedridden, daycare attendance, breastfeeding, age of 2-6 months and household contact with healthcare worker as reported in previous studies $(13,32)$. This is similar to a study done by Adesidaet al among medical students in a tertiary hospital in Lagos, Nigeria (22) and in contrast to studies done in Africa (33-35) plus studies done in United States (36). In this study, the temporal relationship between having surgery and MRSA colonization could not be established due to the study design. However, an earlier cohort study concluded that children going for clean elective surgery need not be screened for MRSA prior to surgery (11).

The MRSA colonization of paediatric age group is particularly of interest for a number of reasons. First, they are a very vulnerable group that need special protection from such virulent organisms. They are at risk of systemic invasion of the organism resulting in life threatening infections. Secondly, for school aged children, the risk of transmission to other children is high and that could rapidly result in epidemics if not well handled with serious effect on the health of the community. Lastly, identifying the special populations at risk of MRSA colonization has implications for its control.

\section{ACKNOWLEDGEMENT}

We acknowledge the management of Nigeria Institute Medical Research (NIMR), Lagos, for granting us access to their molecular laboratory where the PCR test was done.

\section{REFERENCES}

1. Voss A, Doebbeling BN. The worldwide prevalence of methicillin-resistant Staphylococcus

DOI: http://dx.doi.org/10.4314/ejhs.v29i4.10 
aureus. Int. J. Antimicrob. Agents 1995 Apr;5(2):101-6.

2. Frazee BW, Lynn J, Charlebois ED, Lambert L, Lowery D, Perdreau-Remington F. High Prevalence of Methicillin-Resistant Staphylococcus aureus in Emergency Department Skin and Soft Tissue Infections. Ann. Emerg. Med. 2005 Mar;45(3):311-320.

3. Kuehnert MJ, Hill HA, Kupronis BA, Tokars JI, Solomon SL, Jernigan DB. Methicillin-resistantStaphylococcus aureus hospitalizations, United States. Emerg. Infect. Dis. 2005 Jun;11(6):868872.

4. Abdullahi, Iregbu KC. Methicillin-Resistant Staphylococcus aureus in a Central Nigeria Tertiary Hospital. Ann. Trop. Pathol. 2018;9(1):6.

5. Ikeh EI. Methicilin-resistant Staphylococcus aureus (MRSA) at Jos University Teaching Hospital. African J. Clin. Exp. Microbiol. 2003 Jan;4(1):52.

6. Onanuga A, Oyi A, Olayinka B, Onaolapo J. Prevalence of Community-associated Methicillinresistant Staphylococcus aureus (MRSA) among women in Federal Capital Territory (Abuja), Nigeria. African J. Biotechnol. 2002;4(9)

7. Fusi Ngwa CN, Egri-Okwaji MT, Odugbemi T, Iroha E. A study on pediatric nosocomial methicillin - resistant Staphlococcus aureus in Lagos, Nigeria. Int. J. Biol. Chem. Sci. 2007 Oct;1(1):54-60.

8. Olowe O, Eniola K, Olowe R, Olayemi A. Antimicrobial Susceptibility and Beta-lactamase detection of MRSA in Osogbo. SW Nigeria. Nat. Sci. 2007;5(3):44-48.

9. Taiwo S, Onile B, Akanbi II A. MethicillinResistant Staphylococcus Aureus (MRSA) Isolate in Ilorin, Nigeria. African J. Clin. Exp. Microbiol. 2004 Jun;5(2):189-197.

10. Olonitola OS, Olayinka BO, Onanolapo JA. Absence of mecA gene in methicillin resistant Staphlococcus aureus isolated from non-hospital sources in Zaria, Nigeria. Int. J. Nat. Appl. Sci. 2008 Jan;3(2):160-164.

11. Esposito S, Terranova L, Macchini F, Bianchini S, Biffi G, Viganò M, Pelucchi C, Leva E, Principi N. Staphylococcus aureus colonization and risk of surgical site infection in children undergoing clean elective surgery [Internet]. Medicine (Baltimore). 2018 Jul;97(27):e11097.[cited 2019 May 16 ] Available from: http://www.ncbi.nlm.nih.gov/pubmed/29979379

12. Cheesbrough M. District Laboratory Practice in Tropical Countries. 2nd ed. Cambridge: Cambridge University Press; 2002.
13. Soltani B, Taghavi Ardakani A, Moravveji A, Erami M, Haji Rezaei M, Moniri R, Namazi M. Risk Factors for Methicillin Resistant Staphylococcus aureus Nasal Colonization of Healthy Children. Jundishapur J. Microbiol. 2014;7(9):e20025.

14. Onanuga A, Temedie TC. Nasal carriage of multidrug resistant Staphylococcus aureus in healthy inhabitants of Amassoma in Niger delta region of Nigeria. Afr. Health Sci. 2011 Jun;11(2):176-81.

15. Williamson K, Bisaga A, Paquette K, Lovell E. The prevalence of methicillin-resistant Staphylococcus aureus colonization in emergency department fast track patients. World J. Emerg. Med. 2013;4(4):278-9.

16. Brown AF, Leech JM, Rogers TR, McLoughlin RM. Staphylococcus aureus Colonization: Modulation of Host Immune Response and Impact on Human Vaccine Design. Front. Immunol. 2014 Jan; $4: 507$.

17. Robinson J. Colonization and infection of the respiratory tract: What do we know? Paediatr. Child Health 2004 Jan;9(1):21-4.

18. Sakr A, Brégeon F, Mège J-L, Rolain J-M, Blin O. Staphylococcus aureus Nasal Colonization: An Update on Mechanisms, Epidemiology, Risk Factors, and Subsequent Infections. Front. Microbiol. 2018;9:2419.

19. von Eiff C, Becker K, Machka K, Stammer H, Peters G. Nasal Carriage as a Source of Staphylococcus aureus Bacteremia. N. Engl. J. Med. 2001 Jan;344(1):11-16.

20. Crossley KB. Staphylococci in human disease. Wiley-Blackwell; 2010.

21. Chigbu C. O, Ezeronye OU. Antibiotic resistant Staphylococcus aureus in Abia State of Nigeria. African J. Biotechnol. 2003 Oct;2(10):374-378.

22. Adesida SA, Abioye OA, Bamiro BS, Brai BIC, Smith SI, Amisu KO, Ehichioya DU, Ogunsola FT, Coker AO. Associated risk factors and pulsed field gel electrophoresis of nasal isolates of Staphylococcus aureus from medical students in a tertiary hospital in Lagos, Nigeria. Braz. J. Infect. Dis. 2007 Feb;11(1):63-9.

23. Adelowo K, OKon K, Denue B, Ladan J, Tahir F, Uba A. Methicillin-Resistant Staphylococcus Aureus (MRSA) Colonisation level among Patients seen at a Tertiary Hospital in Maiduguri, Nigeria. J. Med. Med. Sci. 2014;5(10):238-244.

24. Gorwitz RJ, Kruszon-Moran D, McAllister SK, McQuillan G, McDougal LK, Fosheim GE, Jensen BJ, Killgore G, Tenover FC, Kuehnert MJ. Changes in the Prevalence of Nasal Colonization with Staphylococcus aureus in the United States, 
2001-2004. J. Infect. Dis. 2008 May;197(9):1226-1234.

25. Denton M, O'Connell B, Bernard $\mathrm{P}$, Jarlier V, Williams Z, Henriksen AS. The EPISA study: antimicrobial susceptibility of Staphylococcus aureus causing primary or secondary skin and soft tissue infections in the community in France, the UK and Ireland. J. Antimicrob. Chemother. 2008 Feb;61(3):586-588.

26. Nworie A, Azi S, Ibiam G, Egwu I, Odoh I, Okereke E, Oti-Wilberforce R, Eze U, Obi I. Nasal carriage of methicillin resistant Staphylococcus aureus amongst meat sellers in Abakaliki Metropolis, Ebonyi State, Nigeria. Microbiol. Res. Int. 2013 Dec;1(3):48-53.

27. Chen C-J, Huang Y-C. Community-acquired methicillin-resistant Staphylococcus aureus in Taiwan. J. Microbiol. Immunol. Infect. 2005 Dec;38(6):376-82.

28. Olonitola OS, INabo HI, Olayinka BO, Bugo ID. Nasal carriage of methicillin-resistant Staphylococcus aureus by primary school pupils in a University Staff School, Zaria, Nigeria. Int. J. Biol. Chem. Sci. 2007 Oct;1(1):71-75.

29. Iroha I, Nwakaeze E, Oji E, Nwosu K, Ayogu A. Prevalence of Methicillin-Resistant Staphylococcus aureus (MRSA) from Nasal Swabs of Hospitalized Children in Abakaliki. Niger. J. Biotechnol. 2012;24(0):1-6.

30. Kalra L, Camacho F, Whitener CJ, Du P, Miller M, Zalonis C, Julian KG. Risk of methicillinresistant Staphylococcus aureus surgical site infection in patients with nasal MRSA colonization. Am. J. Infect. Control 2013 Dec;41(12):1253-1257.

31. Ateba Ngoa U, Schaumburg F, Adegnika AA, Kösters K, Möller T, Fernandes JF, Alabi A, Issifou S, Becker K, Grobusch MP, Kremsner PG, Lell B. Epidemiology and population structure of Staphylococcus aureus in various population groups from a rural and semi urban area in Gabon, Central Africa. Acta Trop. 2012 Oct;124(1):4247.

32. Chen C-H, Kuo K-C, Hwang K-P, Lin T-Y, Huang Y-C. Risk factors for and molecular characteristics of methicillin-resistant Staphylococcus aureus nasal colonization among healthy children in southern Taiwan, 2005-2010 [Internet]. J. Microbiol. Immunol. Infect. 2018 Sep;[cited 2019 May 16 ] Available from: http://www.ncbi.nlm.nih.gov/pubmed/30274893

33. Song J-H, Hsueh P-R, Chung DR, Ko KS, Kang C-I, Peck KR, Yeom J-S, Kim S-W, Chang H-H, Kim Y-S, Jung S-I, Son JS, So TM, Lalitha MK,
Yang Y, Huang S-G, Wang H, Lu Q, Carlos CC, Perera JA, Chiu C-H, Liu J-W, Chongthaleong A, Thamlikitkul V, Van PH, Song J-H, Chung DR, Yeom J-S, Lee H, Kim S-W, Chang H-H, Kim YS, Jung S-I, Son JS, So TMK, Thamlikitkul V, Chongthaleong A, Hsueh P-R, Chiu C-H, Liu DJW, Lalitha MK, Mathai D, Perera J, Hung Van P, Van Ngoc T, Carlos CC. Spread of methicillinresistant Staphylococcus aureus between the community and the hospitals in Asian countries: an ANSORP study. J. Antimicrob. Chemother. 2011 May;66(5):1061-1069.

34. Azeez - Akande O, Utsalo S, Epoke J. Distribution and antibiotic susceptibility pattern of methicillin-resistant Staphylococcus aureus isolates in a university Teaching hospital in Nigeria. Sahel Med. J. 2009 Feb;11(4):142-147.

35. Mejía C, Zurita J, Guzmán-Blanco M. Epidemiology and surveillance of methicillinresistant staphylococcus aureus in Latin America. Braz. J. Infect. Dis. 2010 Dec;14 Suppl 2:S79-86.

36. Mainous AG, Hueston WJ, Everett CJ, Diaz VA. Nasal Carriage of Staphylococcus aureus and Methicillin-Resistant $\mathrm{S}$ aureus in the United States, 2001-2002. Ann. Fam. Med. 2006 MarApr;4(2):132-7. 